\title{
Effects of wind farm on surface soil in desert steppe, China
}

\author{
Long Chen ${ }^{1}$, Songyao $\mathrm{Ma}^{1,{ }^{*}}$, Liping Shang ${ }^{1}$, Aijun Ding ${ }^{2}$, and Zeyu Teng ${ }^{2}$ \\ ${ }^{1}$ Gansu Natural Energy Research Institute, Lanzhou 730046, China \\ ${ }^{2}$ Key Laboratory of Ecohydrology of Inland River Basin, Northwest Institute of Eco-Environment and Resources, Chinese Academy of \\ Sciences, Lanzhou 730000, China
}

\begin{abstract}
In recent years, the wind farm has developed rapidly in northern China. However, the construction and operation of wind farm directly or indirectly result in the change of soil structure, thus affecting the regional ecological environment. According to the characteristics of wind turbine engineering, the disturbance area of wind farm can be divided into the core disturbed zone, the secondary disturbed zone and the indirect disturbed zone. A field study was conducted to investigate the physical and chemical properties of surface soil in different disturbed zones. The results show that: (1) soil compaction, soil bulk density and soil salinity of the surface soil are sensitive to wind farm disturbance; compared with the undisturbed zone, there are still significant differences between the core disturbed zone and the secondary disturbed zone; (2) after nearly 10 years of natural recovery, apart from the phosphorus element, there are little differences of surface soil nutrients in different disturbed zones; (3) the impact of wind farm on surface soil will be gradually eliminated over time, but continuous and frequent disturbances caused by engineering maintenance during its operation should be avoided if possible.
\end{abstract}

\section{Introduction}

Wind energy, with its clean and renewable features, has developed rapidly in recent years ${ }^{[1]}$. The installed capacity of wind power in China has expanded year by year, mainly in the regions of northeast, northwest and north China, together accounting for more than $90 \%$ of the country's wind energy resources ${ }^{[2]}$. However, the concentrated areas of wind farm in northwest China are also ecologically fragile areas, where soil erosion and desertification are long-term ecological problems ${ }^{[3-4]}$. The construction and operation of wind farm directly or indirectly disturb the soil, especially in the excavation area of the tower foundation, causing profound damage of soil structure. Meanwhile, in the operation process of wind farm, due to the change of local micro-climate conditions as well as engineering maintenance and repair, the proper growth and development of vegetation is affected in an indirect way ${ }^{[5-8]}$.

Wind turbine engineering has its own characteristics, and its disturbance to the soil presents a point and linear pattern. During its construction, several meters of soil excavation area will be formed at the base of each wind turbine tower and the power transmission \& transformation device, making the deep soil turn outwards, which completely destroys the original structure of surface soil and changes its physical and chemical properties. In addition, the constructions of power transmission \& transformation devices and access roads have left the soil surface in bad damage, leading to higher degree of soil erodibility, and lower resistance on water and wind erosion, thereby aggravating soil desertification and soil erosion ${ }^{[9]}$.

Surface soil $(0-20 \mathrm{~cm})$, as interface of land and atmosphere, is one of the most sensitive ecological elements to external disturbances. In recent years, a number of scholars have begun to pay attention to this aspect of the problem ${ }^{[6,10]}$, but there is few available information and also a lack of more systematic and continuous research. In view of this, the study, through the method of space instead of time, taking soil samples in wind farm's different disturbed zones as the research object, from the aspect of physical and chemical properties, investigates and analyzes the effects of wind farm construction and operation on surface soil after its nearly 10 years of natural recovery, so as to provide basic data and theoretical basis for soil restoration, utilization and management under wind farm disturbance in China's northwest arid region.

\section{Materials and Methods}

\subsection{Study area}

The wind farm $\left(36^{\circ} 58^{\prime}-37^{\circ} 10^{\prime} \mathrm{N}, 103^{\circ} 56^{\prime}-104^{\circ} 02^{\prime} \mathrm{E}\right)$ is located in Jingtai County, Gansu Province, at the intersection of the Qinghai-Tibet Plateau, the Loess Plateau and the Mongolian Plateau, which is the aggregation area of wind energy resource in the east section of Hexi Corridor. The wind farm has been running continuously for nearly 10 years since its construction in 
2010 , with a total installed capacity of $99 \mathrm{MW}$ and an area of $1092.15 \mathrm{hm}^{2}$. The area is a temperate continental climate with an average annual precipitation of $217.6 \mathrm{~mm}$, an average annual temperature of $10^{\circ} \mathrm{C}$, a frost-free period of $159 \mathrm{~d}$ throughout the year, an annual average wind speed of $2.57 \mathrm{~m} \cdot \mathrm{s}^{-1}$, and a dominant wind direction of ES-EES.

As the study area is in the transition zone from grassland to desert, the zonal vegetation includes not only deserts such as Salsola passerine desert and Reaumuria soongorica desert, but also desert steppe dominated by Stipa breviflora. The arid soil belongs to the sierozem and brown soil. Meanwhile, the study area, dominated by animal husbandry, is a semi-agricultural and semi-pastoral area, and mainly depends on irrigated agriculture, so there are also hidden areas of silt and saline soil.

\subsection{Field study design}

According to the construction characteristics of wind farm and its operation, the research area is divided into the core disturbed zone, the secondary disturbed zone and the indirect disturbed zone (Fig. 1). The zone outside the wind farm in which the soil type is similar to that of wind farm, is defined as an undisturbed zone. Soil samples were collected separately.

The core disturbed zone refers to the area where the wind turbine tower base, power transmission \& transformation device and the surrounding earthwork are completely excavated, with the deep soil turned outwards and soil structure in full damage; the secondary disturbed zone refers to the area where the soil is not excavated but is piled and buried by the excavated soil of core disturbed zone and rolled by the engineering vehicles; the indirect disturbed zone is an area within the wind farm that is not directly affected by the project.

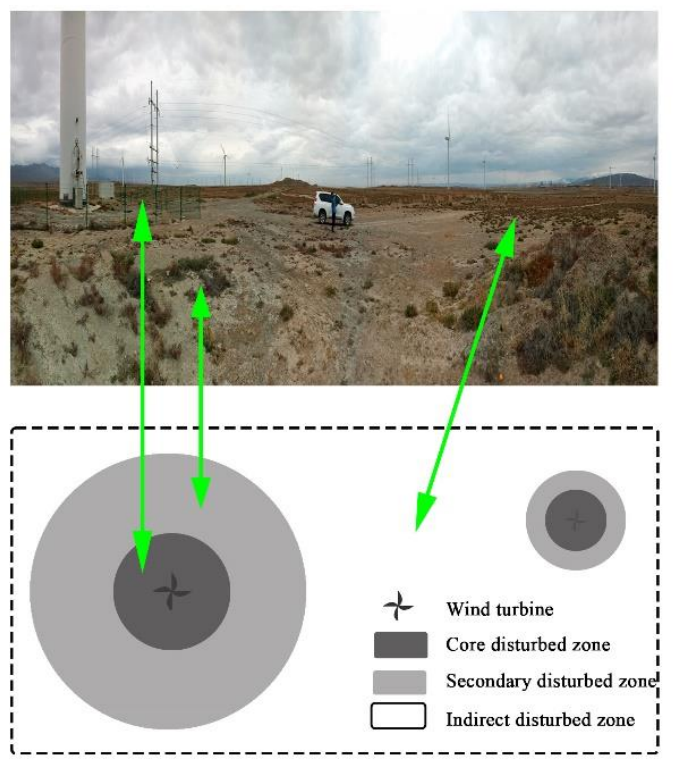

Fig. 1. Wind farm disturbance series

\subsection{Soil samples collection and determination}

Soil samples were collected in July 2018. With the main wind direction, three complete disturbance series were selected in the upwind direction, the wind field and the downwind direction, and sample plots were set for each series. Each sample plot was divided into a core disturbed zone, a secondary disturbed zone and an indirect disturbed zone, and each small zone was randomly arranged with three sampling points. The soil compaction was measured with a soil compaction meter (DIK5553, Japan), while soil bulk density was measured with a $0-20 \mathrm{~cm}$ soil layer sample using a ring knife. A 0-20 cm soil layer sample was collected with a soil drill, and brought back to the laboratory in cloth bags. The samples were air-dried and sieved for the test of physical and chemical properties.

The $\mathrm{pH}$ value was measured through a $\mathrm{pH}$ meter $(1 / 5$ soil-water ratio), and the electrical conductivity (EC) was measured through a conductivity meter $(1 / 5$ soil-water ratio). $\mathrm{CO}_{3}{ }^{2-}, \mathrm{HCO}_{3}{ }^{-}$was determined by double indicator neutralization method, $\mathrm{SO}_{4}{ }^{2-}$ was determined by EDTA indirect complexometric titration, $\mathrm{Cl}^{-}$by $\mathrm{AgNO}_{3}$ titration, $\mathrm{Ca}^{2+}$ and $\mathrm{Mg}^{2+}$ by EDTA titration, and $\mathrm{K}^{+}$and $\mathrm{Na}^{+}$by flame photometer. The soil organic carbon was measured through an external heating method of potassium dichromate. Total carbon and total nitrogen contents were determined by elemental analyzer (i.e. Maco-cube Elementar, Germany), and total phosphorus was determined by sulfuric acid - perchloric acid digestion molybdenum antimony colorimetric method. The hydrolysable nitrogen was determined by alkali diffusion method; the available phosphorus was extracted with sodium bicarbonate - molybdenum ruthenium anticolorimetric method; and the available potassium was determined by ammonium acetate extraction - flame photometry ${ }^{[11]}$.

\subsection{Statistical analysis}

The data was statistically analyzed by using Excel and SPSS 10.0. One-way analysis of variance was used to analyze the difference significantly. The least significant difference (LSD) method for multiple comparisons was used to compare the differences between different types of soils with $95 \%$ of reliability.

\section{Results and discussion}

\subsection{Soil physical properties of wind farm disturbed zones}

In this study, soil compaction and soil density were selected to investigate the effect of wind farm disturbance on soil physical properties. Soil compaction is an important indicator to measure the existence and volume ratio of three-phase substances in soil. It regulates soil water, fertilizer, gas, heat, and its physical, chemical and biological processes and other factors ${ }^{[12]}$, and directly affects the growth and development of vegetation. Soil bulk density is a comprehensive indicator of soil physical properties ${ }^{[13]}$. It is a comprehensive representation of soil permeability, infiltration performance, water-holding capacity, solute migration characteristics and soil erosion resistance ${ }^{[14]}$. 


\subsubsection{Soil compaction characteristics}

The disturbance degree of wind farm has a significant effect on the compactness of the surface soil $(p<0.05)$. As the degree of disturbance increases, the soil compaction becomes larger (Fig. 2, A). Compared with the undisturbed zone, the soil compaction is much larger in the core disturbed zone with a significant level of difference, followed by the secondary disturbed zone, and then the indirect disturbed zone, but the latter two do not reach a significant level. This shows that the deeper the disturbance is, the greater the impact on soil compaction becomes. After nearly 10 years of natural restoration, the soil compaction among the secondary disturbed zone, the indirect disturbed zone and the undisturbed zone is no longer significant, and only the core disturbed zone shows significant difference, which indicates that the difference

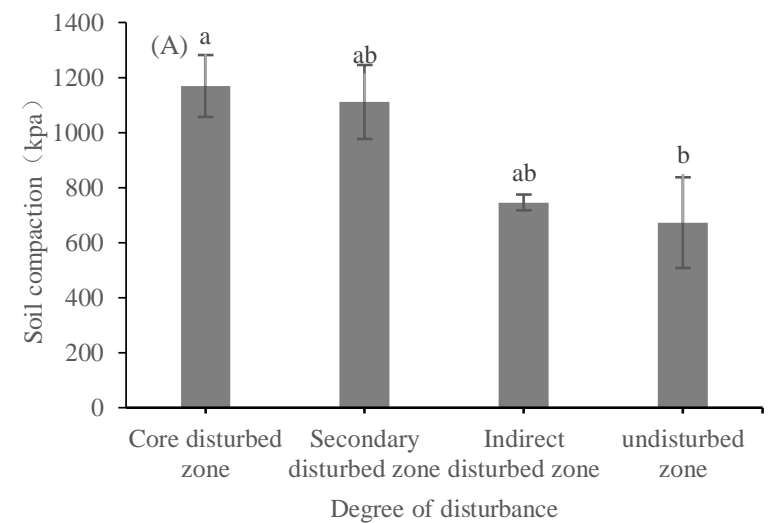

in surface soil compaction has been gradually narrowed between the disturbed zones over time.

\subsubsection{Soil bulk density characteristics}

The difference in soil bulk density in different disturbed zones of wind farm differs from soil compaction, but also reaches a significant level $(p<0.05)$. The soil density in the

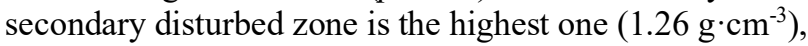
followed by the indirect disturbed zone $\left(1.12 \mathrm{~g} \cdot \mathrm{cm}^{-3}\right)$, and then the undisturbed zone $\left(1.05 \mathrm{~g} \cdot \mathrm{cm}^{-3}\right)$, with the lowest density of core disturbed zone $\left(1.04 \mathrm{~g} \cdot \mathrm{cm}^{-3}\right)$ (Fig. 2, B). The soil bulk density value in the study area is overall small, which is related to the arid environment. The soil surface has characteristics of large evaporation, weak

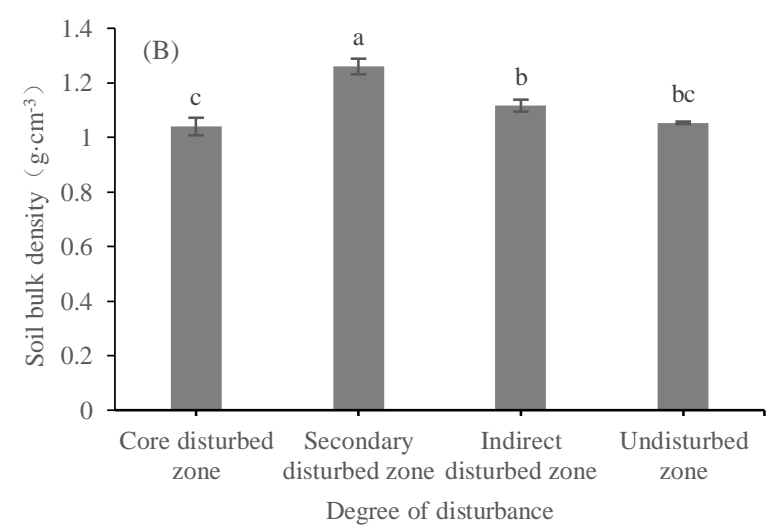

Fig.2. Soil compaction and soil bulk density in different disturbed zones. (A) represents soil compaction, and (B) represents soil bulk density. (Notes: different lowercase letters in the figure indicate significant differences, $p<0.05$, the same below.)

water-holding capacity, poor wind erosion resistance, and large soil porosity. The bulk density of the secondary disturbed zone is larger than that of the undisturbed zone, with a significant level of difference $(p<0.05)$. This is mainly because the secondary disturbed zone is often interfered by the rolling of engineering vehicles and human activities of maintenance. However, the differences in soil density among core disturbed zone, indirect disturbed zone and undisturbed zone do not reach a significant level $(p>0.05)$, which also demonstrates that after many years of natural restoration, the soil in the disturbed zones of wind farm has slowly returned to normal.

\subsection{Soil chemical properties of wind farm disturbed zones}

\subsubsection{Influence of wind farm disturbance on soil salinity}

Through measuring the eight ions including $\mathrm{CO}_{3}{ }^{2-}, \mathrm{HCO}_{3}{ }^{-}$, $\mathrm{SO}_{4}^{2-}, \mathrm{Cl}^{2}, \mathrm{Ca}^{2+}, \mathrm{Mg}^{2+}, \mathrm{K}^{+}, \mathrm{Na}^{+}$in the surface soil of wind farm disturbed zones, it is found that in the surface soil the dominant anions are $\mathrm{SO}_{4}{ }^{2-}$ and $\mathrm{Cl}^{-}$, and the cations are $\mathrm{Na}^{+}$ and $\mathrm{Ca}^{2+}$. It mainly belongs to sulfate-chloride salted soil type. The total salt content of the surface soil is not too high, and the soil salinization is not that serious. The total salt content in the core disturbed zone is up to $4.66 \mathrm{~g} \cdot \mathrm{kg}^{-1}$, followed by the undisturbed zone $\left(3.79 \mathrm{~g} \cdot \mathrm{kg}^{-1}\right)$, and then the indirect disturbed zone $\left(2.73 \mathrm{~g} \cdot \mathrm{kg}^{-1}\right)$, while the total salt content in the secondary disturbed zone $\left(0.89 \mathrm{~g} \cdot \mathrm{kg}^{-1}\right)$ is obviously lower than that of the core disturbed zone and the undisturbed zone (Fig. 3, A). In the meantime, it is found that the change law of soil conductivity is almost consistent with that of soil total salt (Fig. 3, B). This also shows that the soil conductivity can indirectly reflect the soil salinity ${ }^{[15]}$.

The surface soil salinity of the core disturbed zone is the highest one, but it does not reach a significant level compared to the undisturbed zone. And the salinity of the secondary disturbed zone is significantly lower than that of the undisturbed zone. It indicates that the construction of wind farm to some extent affects the distribution of soil salinity. For example, at the beginning of its construction, turning the deep soil outwards in the core disturbed zone might cause certain change of soil salinity, while after many years of natural recovery, the soil salinity tends to be consistent. The descending soil surface salinity in the secondary disturbed zone well reflects the sensitivity of soil salinity in the frequently disturbed maintenance area after its operation of wind farm. However, it does not mean that the disturbance reduces the salt content, making the soil tend to be good, but probably indicates that the salinity in the secondary disturbed zone is transferred to 
the deep layer of the soil, which still needs further research.

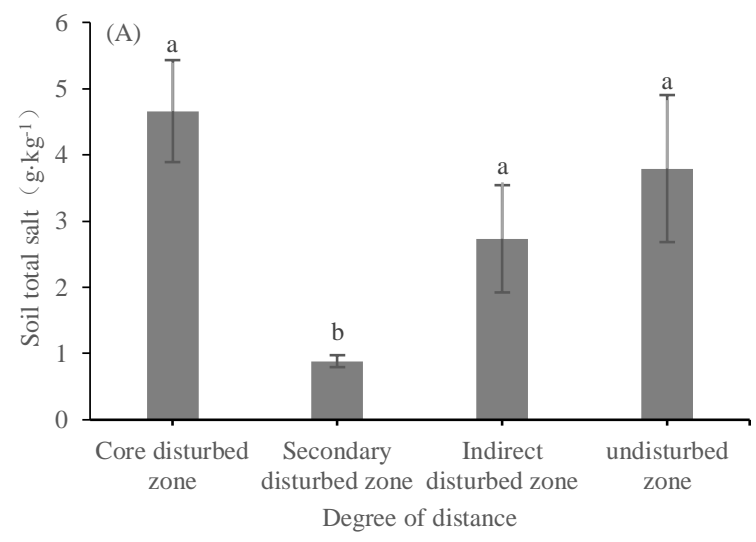

Fig. 3. Soil total salt and soil electrical conductivity in different disturbed zones. (A) represents soil total salt, and (B) represents soil electrical conductivity

Soil nutrients, as the major elements of influencing soil fertility and quality, are key indicators of soil evaluation, which to a large extent have an impact on the restoration, reconstruction and growth of vegetation.

The soil in the study area is alkaline and the average $\mathrm{pH}$ value is above 7.5. This is mainly influenced by the local climatic condition, with strong soil evaporation and high degree of salinization, especially on the surface. From the disturbance degree of wind farm, the soil alkalization of the secondary disturbed zone is the highest one and also significantly higher than that of the core disturbed zone and the undisturbed zone. It has something to do with the long-term and continuous disturbance of wind farm operation. However, in the areas that are rarely affected by engineering disturbances, the $\mathrm{pH}$ value is not significant different (Table 1).

By testing soil nutrients such as soil organic carbon,

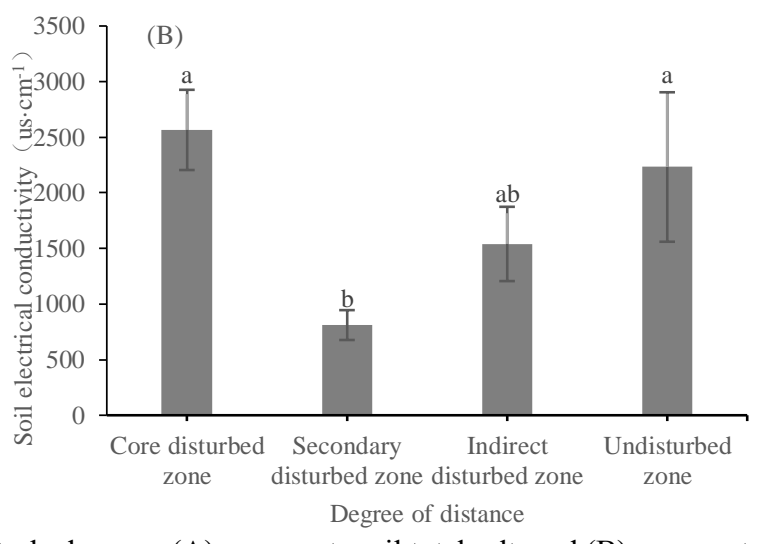

\subsubsection{Influence of wind farm disturbance on soil nutrients}

total nitrogen, total carbon, total phosphorus, and available nitrogen, available phosphorus, and available potassium, it is found that the contents of organic carbon, total carbon, total nitrogen, available nitrogen, and available potassium do not show significant differences in different disturbed zones, only with total phosphorus and available phosphorus reaching a significant level of difference (Table 1). The total phosphorus content in three disturbed zones are significantly higher than that of the undisturbed zone, while the available phosphorus content in the indirect disturbed zone is the highest one, followed by the core disturbed zone, the secondary disturbed zone and the undisturbed zone consecutively. These differences may be related to the way of land use ${ }^{[16-17]}$, because the vegetation succession series in different disturbed zones are not synchronized, with various vegetation types, which may have nothing to do with wind farm disturbance

Table1. Soil nutrients properties in different disturbed zones

\begin{tabular}{|c|c|c|c|c|c|c|c|c|}
\hline & $\mathrm{pH}$ & $\begin{array}{l}\text { Organic } \\
\text { carbon }\left(\mathrm{g} \cdot \mathrm{kg}^{-1}\right)\end{array}$ & $\begin{array}{l}\begin{array}{l}\text { Total } \\
\text { carbon } \\
\left(\mathrm{g} \cdot \mathrm{kg}^{-1}\right)\end{array} \\
\end{array}$ & $\begin{array}{l}\text { Total nitrogen } \\
\left(\mathrm{g} \cdot \mathrm{kg}^{-1}\right)\end{array}$ & $\begin{array}{l}\text { Total phosphorus } \\
\left(\mathrm{g} \cdot \mathrm{kg}^{-1}\right)\end{array}$ & $\begin{array}{l}\text { Available } \\
\text { nitrogen }\left(\mathrm{mg} \cdot \mathrm{kg}^{-1}\right)\end{array}$ & $\begin{array}{l}\text { Available } \\
\text { phosphorus }\left(\mathrm{mg} \cdot \mathrm{kg}^{-1}\right)\end{array}$ & $\begin{array}{l}\text { Available } \\
\text { potassium }\left(\mathrm{mg} \cdot \mathrm{kg}^{-1}\right)\end{array}$ \\
\hline Core disturbed zone & $7.60 \pm 0.67 \mathrm{~b}$ & $9.91 \pm 1.07 \mathrm{a}$ & $19.77 \pm 0.87 \mathrm{a}$ & $0.87 \pm 0.07 \mathrm{a}$ & $1.22 \pm 0.10 \mathrm{a}$ & $28.18 \pm 3.50 \mathrm{a}$ & $18.45 \pm 4.31 \mathrm{ab}$ & $244.00 \pm 24.73 \mathrm{a}$ \\
\hline Secondary disturbed zone & $7.85 \pm 0.44 \mathrm{a}$ & $10.16 \pm 0.87 \mathrm{a}$ & $18.07 \pm 0.66 \mathrm{a}$ & $0.85 \pm 0.04 \mathrm{a}$ & $1.15 \pm 0.02 \mathrm{a}$ & $28.90 \pm 4.25 \mathrm{a}$ & $14.61 \pm 2.15 b$ & $277.78 \pm 43.74 \mathrm{a}$ \\
\hline Indirect disturbed zone & $7.70 \pm 0.09 \mathrm{ab}$ & $10.18 \pm 0.54 \mathrm{a}$ & $18.91 \pm 0.42 \mathrm{a}$ & $0.95 \pm 0.05 \mathrm{a}$ & $1.30 \pm 0.07 \mathrm{a}$ & $23.82 \pm 1.08 \mathrm{a}$ & $26.89 \pm 4.39 \mathrm{a}$ & $268.75 \pm 29.06 \mathrm{a}$ \\
\hline Undisturbed zone & $7.60 \pm 0.08 \mathrm{~b}$ & $10.35 \pm 0.55 \mathrm{a}$ & $17.85 \pm 0.58 \mathrm{a}$ & $0.90 \pm 0.03 \mathrm{a}$ & $0.86 \pm 0.12 b$ & $30.80 \pm 6.20 \mathrm{a}$ & $12.70 \pm 2.88 \mathrm{~b}$ & $215.00 \pm 21.10 \mathrm{a}$ \\
\hline$F$ value & 3.218 & 0.042 & 1.576 & 0.664 & 4.4 & 0.52 & 2.61 & 0.65 \\
\hline significantly & 0.037 & 0.98 & 0.217 & 0.581 & 0.01 & 0.67 & 0.07 & 0.59 \\
\hline
\end{tabular}

Notes: The data in the table is the mean $\pm S E$, and the same letter in the same column data indicates that there is no significant difference at the 0.05 level.

\section{Conclusion}

Through analysis of soil physical and chemical properties in the disturbed zones, it is found that the wind farm construction has a far-reaching impact on soil compaction. Although it has experienced nearly 10 years of natural recovery, the soil compaction in the disturbed zones still shows certain differences, and yet the difference is gradually narrowed over time. The soil bulk density, total salt and EC do not show significant differences in the core disturbed zone, the indirect disturbed zone and the undisturbed zone, while these factors in the secondary disturbed zone show obvious differences compared with other zones. It indicates that after nearly 10 years of natural restoration, the soil bulk density and soil salinity tend to be consistent in different disturbed zones, and the early disturbance brought about by wind farm construction has been basically eliminated. However, due to frequent engineering maintenance, soil density and salinity in the secondary disturbed zone are comparatively sensitive. 
At the same time, it is also found that apart from total phosphorus and available phosphorus, soil nutrients do not show much difference in each disturbed zone. This is caused by the difference of various surface vegetations and has little to do with the disturbance of wind farm.

In short, surface soil physical properties and salinity are sensitive to wind farm disturbance. However, after years of natural recovery, the differences of soil physical and chemical properties are becoming less or even disappeared in areas that are not subject to constant engineering disturbances such as, core disturbed zone and indirect disturbed zone. However, it is due to maintenance and repair work that the secondary disturbed zone is continuously affected, which means minimizing the impact of human activities is necessary in its operation of wind farm.

\section{Acknowledgement}

This work was funded by the cooperation project between Gansu Academy of Sciences and Chinese Academy of Sciences (2017HZ-01), the youth science and technology innovation program of Gansu Natural Energy Research Institute (2018QN-02) and the National Key Research and Development Program of China (2016YFC0501001).

\section{References}

1. I. Dincer, C. Acar, Int. J. Energy Res., 39, 585-606 (2015)

2. China National Renewable Energy Center, China renewable energy industry development report 2017 (China economic publishing house, 2017)

3. T. Wang, Journal of Desert Research, 29, 1-9 (2009)

4. Z. Y. Ouyang, X. K. Wang, H. Miao, Acta Ecologica Sinica, 20, 9-12 (2000)

5. G. Q. Li, X. B. Li, Progress in Geography, 35, 10171026 (2016)

6. Z. L. Li, Research of Soil and Water Conservation, 22, 61-66 (2015)

7. S. Y. Ma, L. Chen, Y. Z. Teng, A. J. Ding, Z. H. Heng, Journal of Desert Research, 39, 186-192 (2019)

8. A. Armstrong, S. Waldron, J. Whitaker, Global Change Biology, 20, 1699-1706 (2014)

9. Z. Liu, J. J. Ma, Journal of Northwest University (Natural Science Edition), 44, 127-132 (2014)

10. Z. J. Jia, J. Li, B. Y. Zhen, F. Wang, Bulletin of Soil and Water Conservation, 38, 241-245 (2018)

11. S. D. Bao, Soil and Agriculture Analysis (China Agriculture Press, 2000)

12. S. G. Xiong, Basic Soil Science, (China Agricultural University Press, 2001)

13. Z. G. Zhang, Q. Xu, Acta Pedologica Sinica, 35, 384$391(1998)$

14. L. L. Zhou, H. Z. Zhu, H. P. Zhong, H. Yang, F. Y. Suo, X. M. Shao, X. J. Zhou, Acta Prataculturae Sinica, 25, 64-75 (2016)
15. H. Y. Liu, P. He, J. P. Cai, R. Z. Wang, J. F. Yin, S. Yang, Y. G. Zhang, Chinese Journal of Soil Science, 47, 85-91 (2016)

16. Z. Q. Teng, X. D. Li, H. G. Han, C. P. Zhang, H. Fu, Acta Prataculturae Sinica, 22, 30-37 (2013)

17. Y. S. Ou, S. R. Zhang, Q. Yu, T. Li, J. Y. Shu, J. Li, Acta Ecologica Sinica, 25, 2776-2781 (2005) 